

\title{
NUMERICAL MODELING OF SOLUTE TRANSPORT IN GROONDHATER
}

\author{
Prepared by: \\ Ian Miller, Kathleen Roman
}

Prepared for Lawrence Livermore Laboratory

By Golder Associates, Inc. Under Contract 8770703

Distribution:

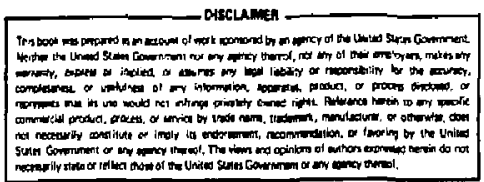

35 coples - Lawrence Livermore Laboratory

10 copies - Golder Associates 


\section{TABLE OF CONTENTS}

\section{Page}

1.0 INTRODUCTION

2.0 THE TEST PROBLEM

3.0 OUTFLOF BOUNDARIES

3.1 PROPOSED SOLUTION FOR OUTFLON BOUNDARIES

4.0 INFLOF BOCNDARIES

5.0 INTERFACES

6.0 NUMERICAL INSTABILITY

7.0 CONCLUDING REMARKS

REFERENCES

APPENDIX: Derivation of Galerkin Finite Element Equations 


\section{LIST OF FIGURES}

FIGURE

1

2

3

4

5

6

Configuration of Solute Transport Problem

Flaite Element Mesh Used in Problem

Flow Net of Axisymetric Rell Problem

Truncated Solute Transport Problem

Concentration Contours From Solute Transport

Analysis, Conrentional Discharge Boundary Conditions

Enlargement of Mesh Shoring Net Rate of Loss

of Fluid at Interelement Boundaries

Concentration Contours From Solute Transport Analysis, Proposed Discharge Boundary Conditions

Concentration Contours From Solute Transport Analysis, Steady-State Solution With Conventional Interface

Concentration Contours From Solute Transport Analysis, Steady-State Soluticn With Proposed Interface

Concentration Contours From Solute Transport Analysis, Transient Analysis: Time = 1 Year

Concentration Contours From Solute Transport Analysis, Transient Analysis: Time $=16$ Years

Concentration Contours From Solute Transport Analysis, Transient Analysis: Time $=40$ Years

Concentration at Hell as Function of Time

Concentration Contours From Solute Transport Analysis, Steady-State Solution With Small Dipersivities

\section{Golder Associates}




\section{PREFACE}

Al though the Galerkin finite element method bas been used for problems of solute transport by flowing groundwater for nearly a decade, there are a number of problems which malse 1 ts use as a routine modeling technique somewhat difficult. This report discusses three problem areas: boundary conditions, interfaces between materials of different permeabilities or radically different velocity vectors, and numerical instability. Methods are proposed for improving these problem areas and are demonstrated using a sample problem. 
As part of the program by the Nuclear Regulatory Comnission to develop an independent capability to assess the safety of high-level nuclear waste repositories, Golder Associates, acting under subcontract to Lawrence Livermore Laboratory, has been enhancing its existing groundwater modeling capability. Th1s capability presently includes finite element methods for two- and three-dimensional analysis of groundwater flow and solute transport. The work presented herein is part of an effort to remove some of the limitations inherent in conventional Galerkin finite element solute transport analysis methods.

Invest1gators using the Galerkin finite element method* for solute transport analysis appear to have frequently encountered difficulties when applying the method to realistic (i.e., complex) problems. The difficulties reported in the literature revolve around two main topics: erratic results in regions of high fluld-pressure gradients or high permeability contrasts and numerical instability when convective transport is dominant over dispersive transport. The numerical instability problem can be readily resolved by simply reflning the mesh size. Unfortunately, such refinement can cause computational costs to rise dramatically. The problems which arise at Interfaces do not disappear when the mesh is refined, and thus apparently can be resolved only by modifying the Galerkin finite element method.

The difficulty with high gradients has been reported by Segol et al. (1975), who attributed it to the presence of discontinudities in the seepage velocity field at the boundaries between elements. They reported that negative solute concentrations were computed in regions of high-pressure

*For a description of the Galerkin finite element method as applied to solute transport, see Pinder, 1973. 
gradients. The solution they proposed was to generate a seepage velocity fleld which was continuous, and they reported greatly improved results when such a ifeld was used. However, forcing the velocity field to be continuous is not necessarily physically realistic, as it is acceptable for the velocity component parallel to an interelement boundary to be discontinuous. This is particularly clear in the case of the boundary between materials of low and high permeability.

An area which has been widely discussed is numerical instability in convection-dominated flow (e.g., see Heinrich et al. 1977). This problem arises when the finite elements are too large and can be resolved (at some expense) by refining the mesh. Alternatively, the use of "upwind weighting" procedures has been proposed (Christie et al. 1976; Heinrich et al. 1977) whereby the Galerkin method is modified slightly with reportedly substantial1y improver results.

D.K, Gartling (1978), in a discussion of the publication by Heinrich et al. (1977), pointed out that what appeared to be numerical instability could of ten be attributed to applying physically unrealistic boundary conditions, e.g., attempting to specify the solute concentration at a discharging boundary. Most reported solutions using Galerkin's method have involved transient problems only and thus have been insensitive to boundary conditions. In this report, boundary conditions are discussed in some detail, particularly with respect to discharging boundartes.

In general, the difficulties encountered in applying Galerkin's method have not been widely reported. In this report, a sample problem which exhlbits all of the difficulties discussed above is presented and procedures to overcome many of then are suggested. 
In order to demonstrate and, hopefully, resolve some of the problems in conventional analyses of solute transport, a simple example problem is defined. As shown in Figure 1, the problem consists of a well in a freshwater aquifer $(1000 \mathrm{mg} / 1$ total dissolved solids, TDS) which is overlain by a phreatic saline aquifer $(10,000 \mathrm{mg} / 1$ TDS). The well does not completely penetrate the freshwater aquifer, and part of the completed section of the well is in the aquitard separating the aquifers. The problem is axisymmetric and is bounded laterally by a constant head boundary at a radius of 1000 meters, which is maintained at a head of 48 meters in both aquifers. The material underlying the lower aquifer is impermeable. The water table in the saline aquifer is subjected to a recharge rate of $0.5 \mathrm{~m} / \mathrm{a}$ (meters per year) less the amount of evapotranspiration, which is a function of the depth of the water table. In the initial condition, the water table is at i depth of 2 meters and the evapotranspiration rate is $0.5 \mathrm{~m} / \mathrm{a}$. Consequently, there is no net recharge. However, as the well is pumped (at a rate of $1.914 \times 10^{6} \mathrm{~m}^{3} / a$ ) and the water table is lowered, the evapotranspiration rate decreases and there is a net recharge of fresh water to the saline aquifer.

\subsection{FINITE ELEMENT KODEL OF FLOW}

The finite element mesh used for the analysis is shown in Figure 2, and the computed steady-state flow solution is shown in Figure 3. Immediatel; above the well the water table has been drawn down from the initial depth of 2 meters to 2.35 meters, and the recharge exceeds the evapotranspiration by 0.088 $\mathrm{m} / \mathrm{a}$. The drawdown decreases with increasing radius, and at a radius of 1000 meters the water table is at a depth of 2.20 meters. Approximately 6.1 percent of the water which is produced at the well originates from recharge, 9.3 percent comes 


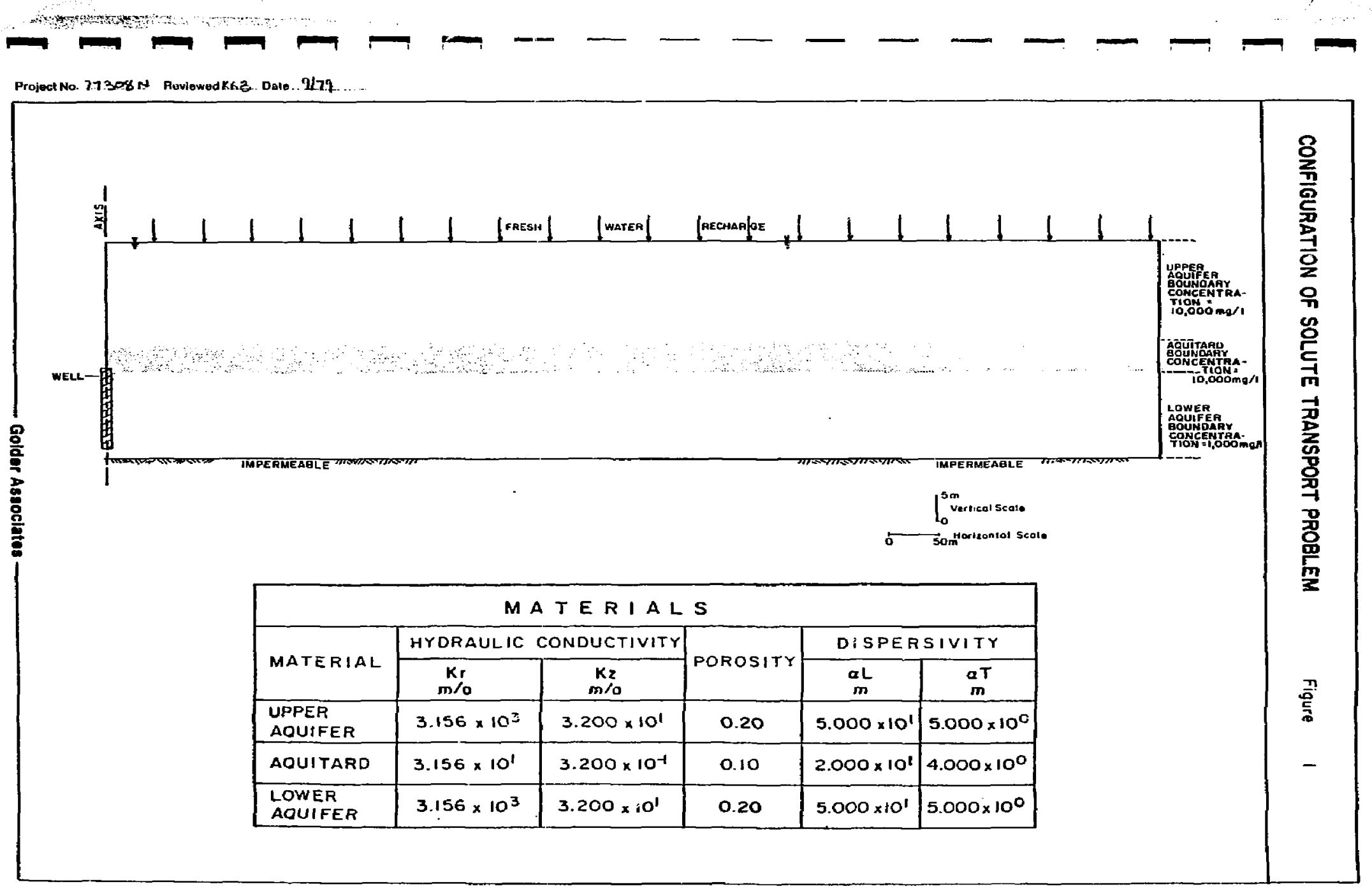




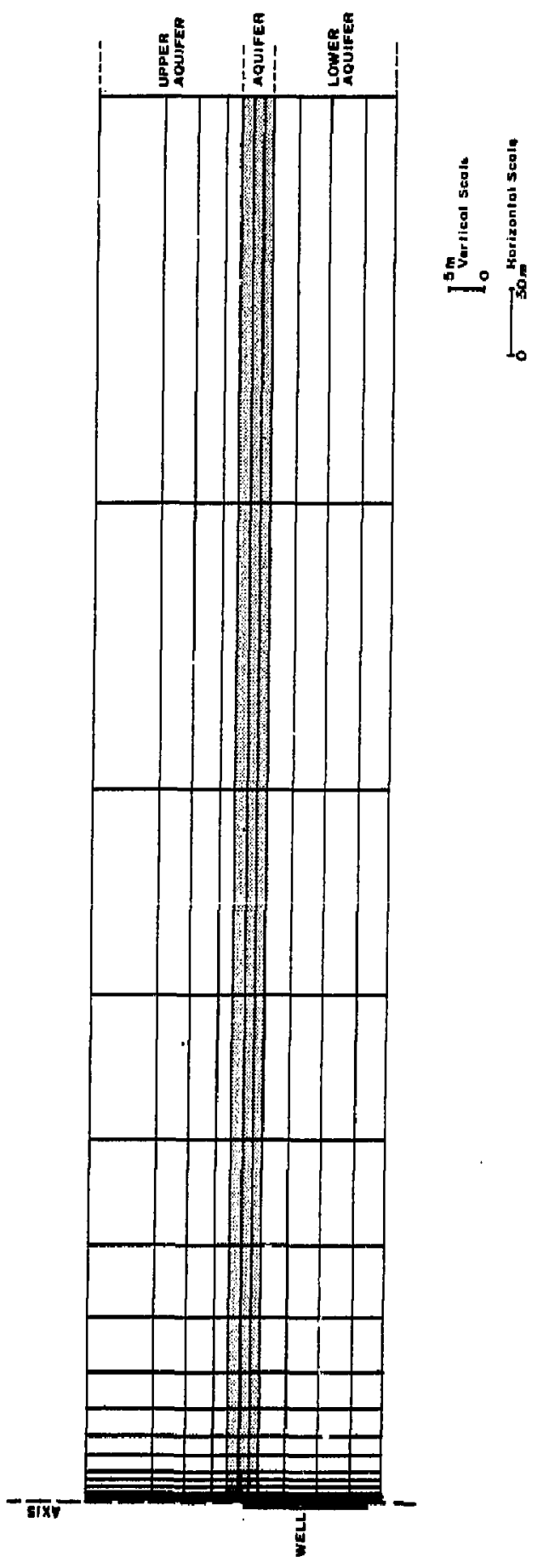




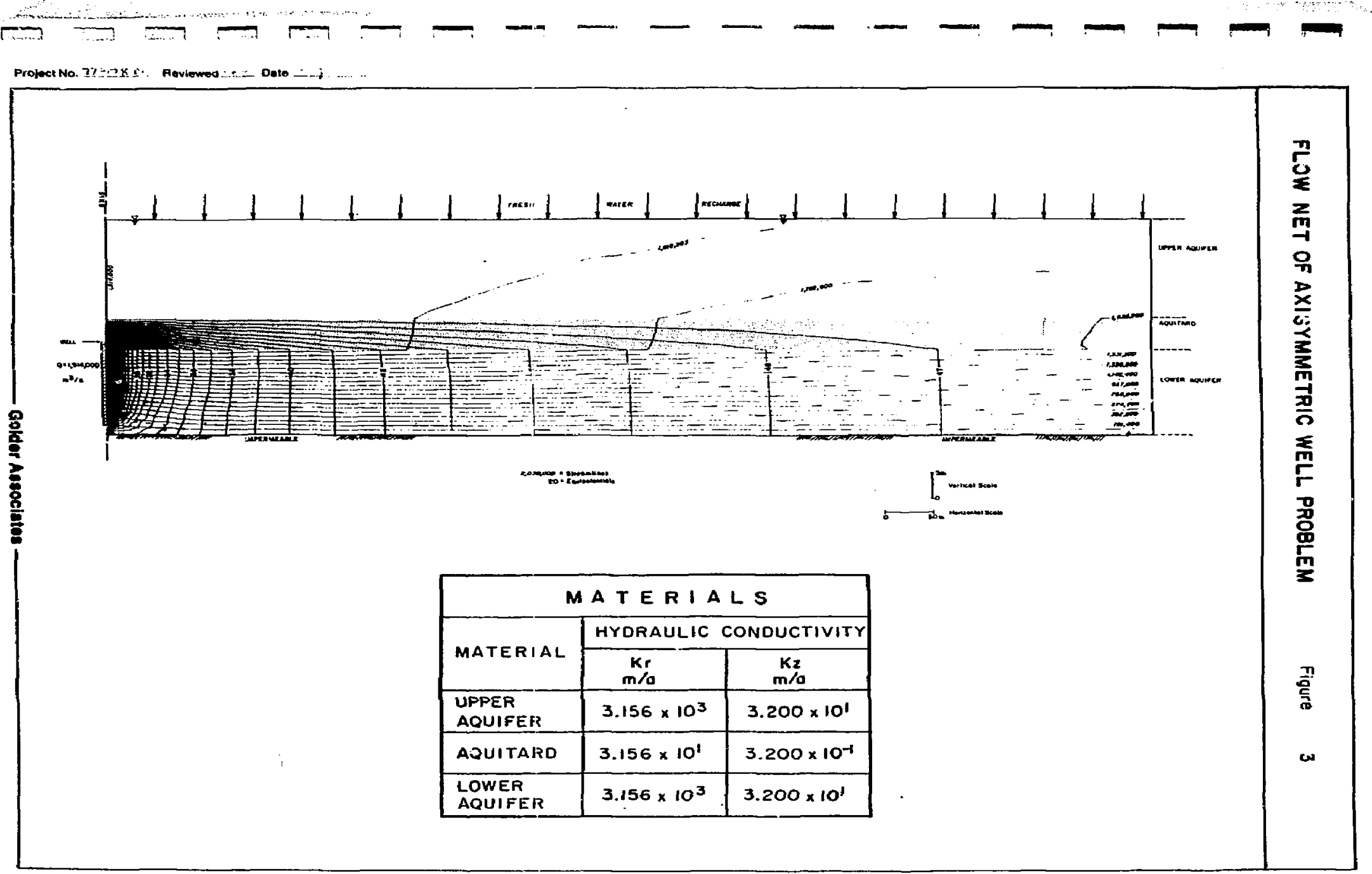


from the overlying saline aquifer, and 84.6 percent comes from the underlying freshwater aquifer.

The quadrilateral finite elements shown in Figure 2 are each composed of four three-node triangular elements clustered around an implicit central node. Each triangle is of constant thickness equal to 2 times its centroidal radius. The effects of the salinity on the fluid density and viscosity are ignored. 
When preparing to do solute transport analyses of the test problem, it was apparent that there wouid be a problem with the Interface between the lower aquifer and the aquitard. The fluid seeping down through the aquitard would be at roughly 10,000 $\mathrm{mg} / 1 \mathrm{TDS}$ wile that in the lower aquifer would be closer to 1000 $\mathrm{mg} / \mathrm{l}$ TDS. The conventional use of interpolation functions in finite element analysis would require a unique common value for the soluta concentration at the interface, which is physically unreasonable. In order to focus on the more imnediate problem of outflow boundaries it pas decided to initialiy analyze only the upper aquifer and the aquitard, thus excluding the lower aquifer from the solute transport miesh. The subsequent investigation of the interface problem is described in Section 5 .

Figure 4 shows the truncated problem which was studied (the truncated portion is outlined with a dashed line). The boundary conditions were assigned as follows: The recharging fluid entering the water table ; pure and hence does not affect the solute transport boundary conditions. (The pater table nodes could al ternatively have been flxed at zero concentration, but that would have interfered with the solute transported radially in from the right-band boundary). At the right-hand boundary both the aquifer and the aquitard are held at a constant 10,000 $\mathrm{mg} / 1$. The lower boundary (the base of the aquitard) and the surface of the weil were treated as conventional "outflow boundarles."

The Appendix presents a simplified derivation of the Galerlin finite element equations used in the SOLTR computer program. The boundary condition developed in the Appendix for handling outflow boundaries (see Equation [A.6]) is based on the assumption that any solute approacking such a boundary will be 


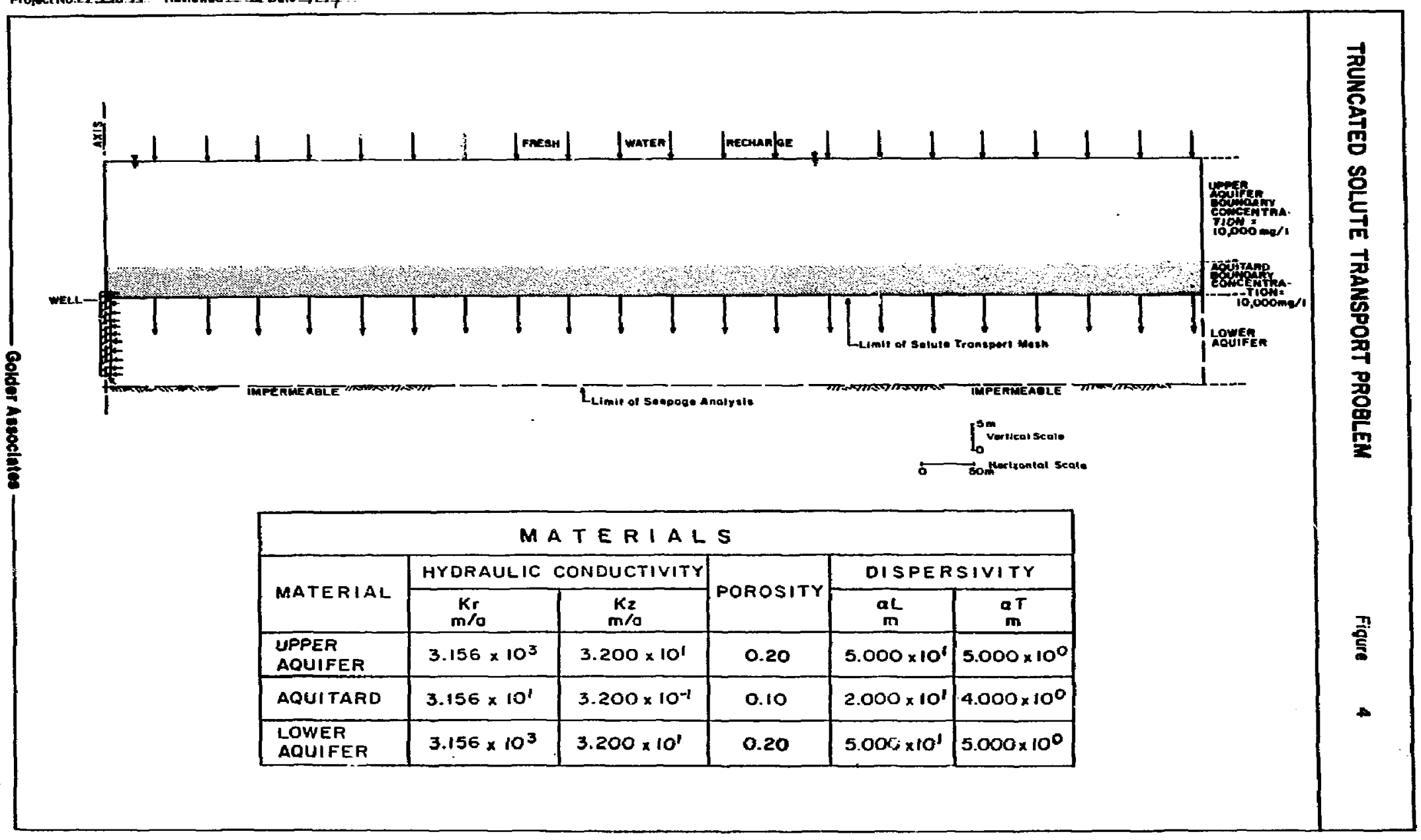


$\rightarrow$

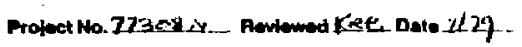

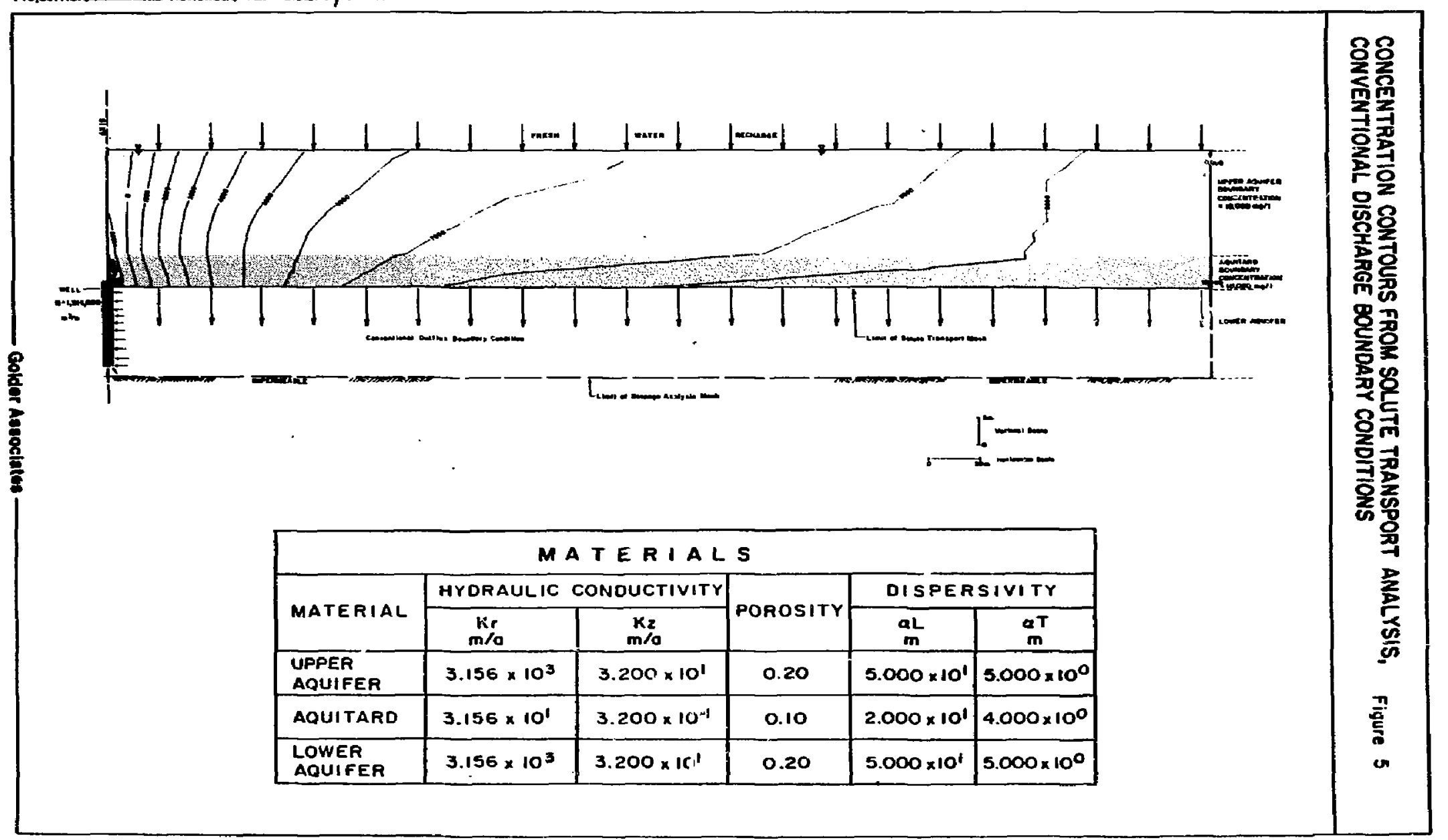


passed through unimpeded. Despite the apparent common sense in such an approach, it can give very poor results, as shown in Figure 5 where the water entering the well from the aquitard has a computed negative solute concentration. Interestingly, the outflow boundary condition behaved very well on a series of other test problems which all involved uniform flow fields. An additional problem appearing in Figure 5 is a diffraction of the concentration contours at the aquifer-aquitard contract in the right-hand part of the mesh.

After some thought, the reason for the poor performance at the outflow boundaries is apparent--in the finite element solution of the seepage problem not all of the outflowing water passes across the external houndaries of the mesh. The reason for this lies in the ray the Galerkin** finite element equations for seepage are developed. Supposing that node 1 is a discharging bouncary node, the steady-state equation for continuity of fluid volume at node $i$ is:

$$
\int_{\Omega} N_{1} \underline{\nabla} \cdot \underline{V} d \Omega=\int N_{S} q d S
$$

where:

$N_{i}$ is the interpolation function for node $i$

$\nabla$ is the divergence operator $\left(\mathrm{L}^{-1}\right)$

$\bar{V}$ is the Darcy velocity $(L T-1)$

$q$ is the specified outflow rate at the discharging boundary (LT-1)

$\Omega$ is the entire flow region

$S_{d}$ is the discharge boundary

$S$ is the surface of the flow region.

**The same is also true of minimal energy procedures which produce the same finite element equations. 
Equation [1] does not force the flow rato across the external boundary to be $q$, but merely specifies the weighted average, in the vicinity of node 1 , of the rate at which fluid is disappearing from the mesh. Precisely where the fluid disappears is not specifled. Thus, in the case of the seepage solution (Figure 2), only part of the fluid leaves the mesh via the external boundaries, and the balance leaves at internal interelement boundaries adjacent to the dischargiag boundary. The effect of ignoring that part of the fluid which leaves from within the mesh is dramatic; the quantity of solute leaving the mesh is apparently less than the quantity entering the mesh at the upstream boundaries. This imbriance can only be resolved by computing large negative concentrations at the discharge point, which cause an additional dispersive flux toward the boundary in order to discharge the same amount of mass as enters the upstream boundaries of the mesh.

Figure 6 is an enlargement of the region near the well, showing the Darcy velocity in each triangular element and the net rate of loss of fluid at each elemert boundary. Note that around internal nodes there is no net loss of fluid (i.e., the sum of the interelement losses around an internal node is zero).

It should be pointed out that the highly discontinuous flow field shown in Figure 6 in fact represents an enlargement of part of a perfectly acceptable seepage analysis result. It is a graphic indication of why seepage analyses which will be used for solute transport models require much finer meshes than conventional seepage analyses.

For seepage analyses where the outflowing boundaries use constant head (Dirichlet) boundary conditions, the situation is identical to that described above. For higher-order finite 


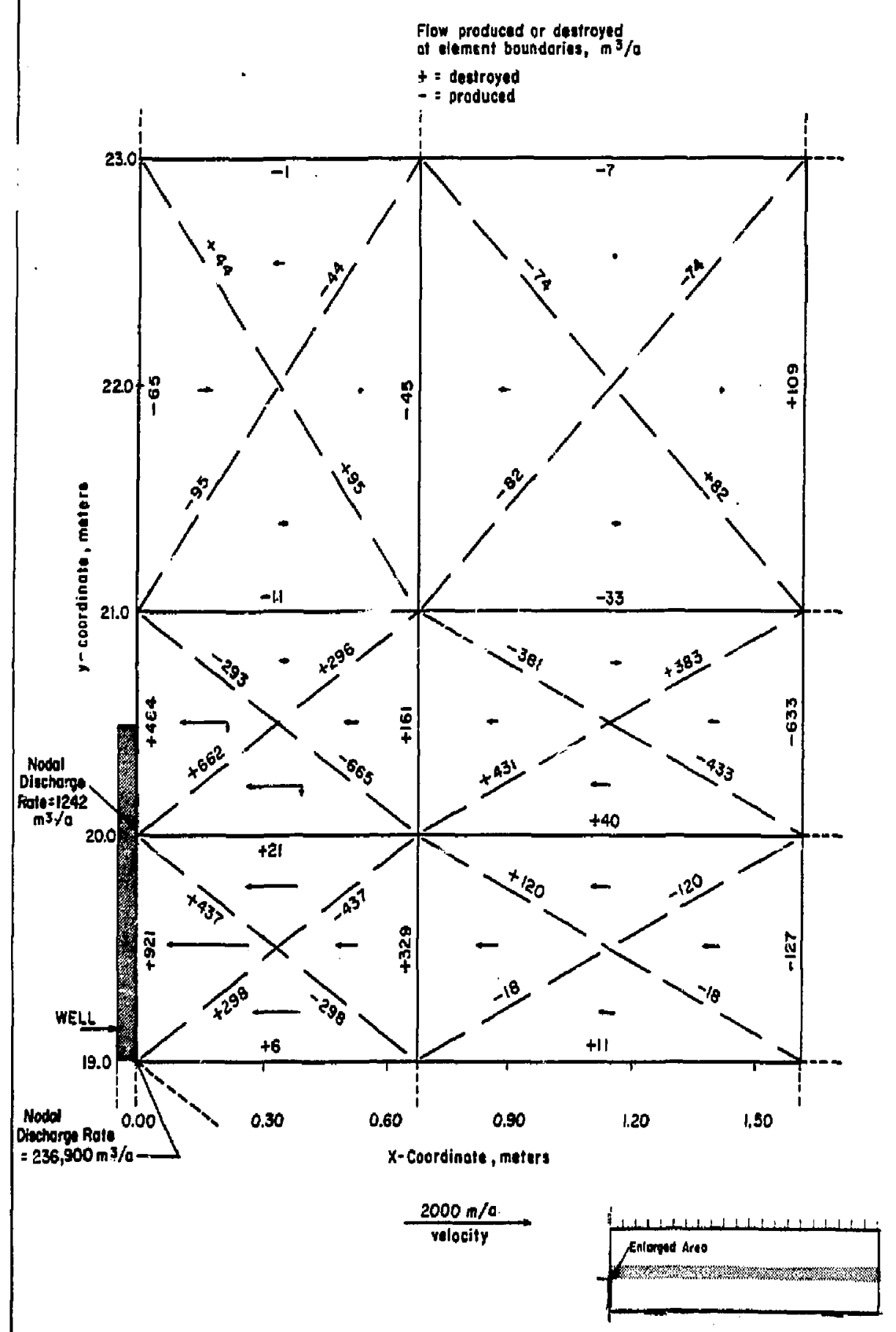


elements or elements where the Darcy velocity is continuous (e.g., Segol et al. 1975), similar problems arise. For higherorder elements the fluid $\nabla 11$ discharge not on! from interelement boundaries but also from $\mathbf{p l t h i n}$ the elements themselves. For elements with continuous velocity fields there will be no interelement losses, but there will be discharge from within the elements. In fact, the problem of discharge occurring from within the mesh will arise in all cases where fluid pressure is the independent field variable. Only in problems where the flow fleld is uniform at the boundary will all the discharge occur across the boundary.

\subsection{PROPOSED SOLUTION FOR OUTFLOT BOUNDARIES}

An approximate solution to the problem posed in solute transport analysis by fluld discharging from within the mesh was readily fourd. For each node identified as a discharge node, the left-hand side of Equation [1] is calculated and that quantity of fluid discharge, multiplied by the node's concentration, is removed from the node. This is accomplished by simply adding the nodal discharge rate to the diagonal term in the solute transport matrix (see Equation [A.7]). The purpose of this calculation is to compute the quantity of fluid leaving the mesh at the node and, by assuming the discharging fluid is all at the same concentration as at the node, remove the correct total amount of solute. The effectiveness of this procedure is demonstrated in Figure 7 , which is the result of a computation using the proposed boundary condition.

The approximate solution described above neglects two aspects of the outflow problem. First, the fluld being discharged (at the boundary or laside the mesh) is not necessarily at a uniform solute concentration. Second, in bighly dispersive media it is apparently possible for dispersive fluxes to also contribute sigaificantly to the solute discharge. 
If cases arise where these two factors are 1mportant, it might prove more acceptable to leave the conventlonal outflow boundary condition in the solution and apply the proposed tecinique only to that portion of the discharge vhich occurs in the interior of the mesh. In all the problems tested to date, the proposed approximate technique has produced acceptable results. 


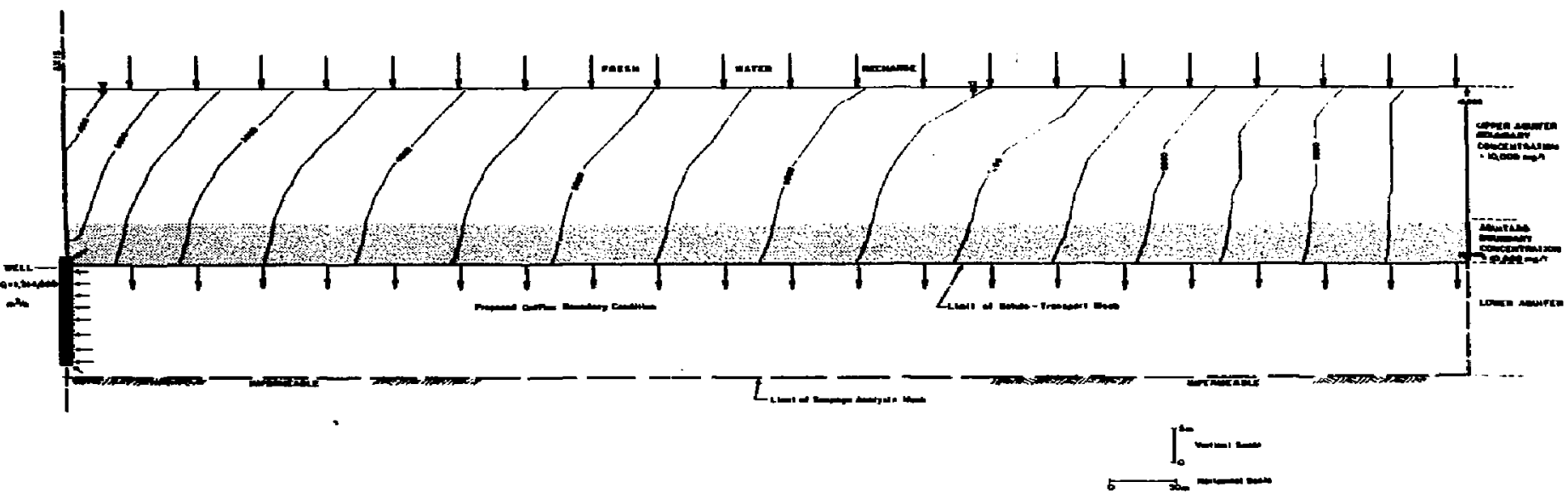

MATERIALS

\begin{tabular}{|c|c|c|c|c|c|}
\hline \multirow{2}{*}{ MATERIAL } & \multicolumn{2}{|c|}{ HYORAULIC CONDUCTIVITY } & \multirow{2}{*}{ POROSITY } & \multicolumn{2}{|c|}{ DISPERSIVITY } \\
\hline & $\begin{array}{c}K r \\
m / a\end{array}$ & $\begin{array}{c}\mathrm{Kz} \\
\mathrm{m} / \mathrm{a}\end{array}$ & & $\frac{a L}{m}$ & $\begin{array}{c}\alpha T \\
m\end{array}$ \\
\hline $\begin{array}{l}\text { UPPER } \\
\text { AQUIFER }\end{array}$ & $3.156 \times 10^{3}$ & $3.200 \times 10^{\prime}$ & 0.20 & $5.000 \times 10^{4}$ & $5.000 \times 10^{0}$ \\
\hline AQUITARO & $3.156 \times 10^{1}$ & $3.200 \times 10^{-1}$ & 0.10 & $2.000 \times 10^{\prime}$ & $4.000 \times 10^{0}$ \\
\hline $\begin{array}{l}\text { LOWER } \\
\text { AQUIFER }\end{array}$ & $3.156 \times 10^{3}$ & $3.200 \times 10^{1}$ & 0.20 & $5.000 \times 10^{1}$ & $5.000 \times 10^{0}$ \\
\hline
\end{tabular}


It is common to specify the solute concentration at nodes on inflow boundaries, a procedure which is not sensitive to the type of problems outlined above for outflow boundaries. Alternatively, it is also possible to specify the rate of addition of solute at an inflow boundary by specifying the solute concentration in the water entering the sides of elements lying on the boundary (see e.g., Equation $[A .6]$ ). This second method is susceptible to exactly the same problems as outlined in Section 3.0 for outflow boundaries, except that in this case it is a part of the fluid entering the mesh which appears at interelement boundarles adjacent to the mesh boundary. In the case of inflow boundaries there are two simple ways to resolve the problem: either by specifying a fised concentration at the nodes on the inflow boundary or by first computing the rate of addition of fluid at the inflow node, and then multiplying by the concentration of the incoming fluid and adding as a solute injection rate directly to the right-hand side of the nodal equation. 
fs Indicated in the preceding section, once the outflow boundary condition problem had been resolved the anticipated problem with the interface between the lower aquifer and the aquitard was addressed. Accordingly; a solute transport model of the full problem was prepared using the new outflow boundary condition at the well, the same boundary conditions for the water iable and right-hand side as described in the previous section and the right-hand side edge of tho lower aquifer maintained at $1000 \mathrm{mg} / 1$. Figure 8 shows contours of the computed solute concentrations. Comparing these with Figure 7; it is apparent that the forced compatibility of concentrations between the highly saifne water in the aquitard and the fresher woter in the lower aquifer has; as anticipated, resulted in an unsatisfactory result. An interesting sidelight is that, despite the clearly lubelievable concentrations at the interface, the correct amount of solute is transmitted down from the saline aquifer. The computed concentration at the well is $1722 \mathrm{mg} / 1$, which is close to the expected value of $1776 \mathrm{mg} / 1$. (The figure $1776 \mathrm{mg} / 1$ is due to the origin of the water: 6.1 percent fresh water from recharge, 9.3 percent at $10,000 \mathrm{mg} / 1$ from the upper aquifer, and 84.6 percent at $1000 \mathrm{mg} / 1$ from the lower aquifer.)

At the physical interface, the solute entering the lower aquiler is rapidly dispersed through a "boundary layer." The apparent solution to the interface modeling problem is thus to use several layers of very thin elements in the lower aquifer adjacent to the boundary. There are several drawbacks to this approach. First, it $\$ 1$ il substantially increase the labor involved in generating the mesh and the computer time required to find the solution. Second, the necessary thickness of the 


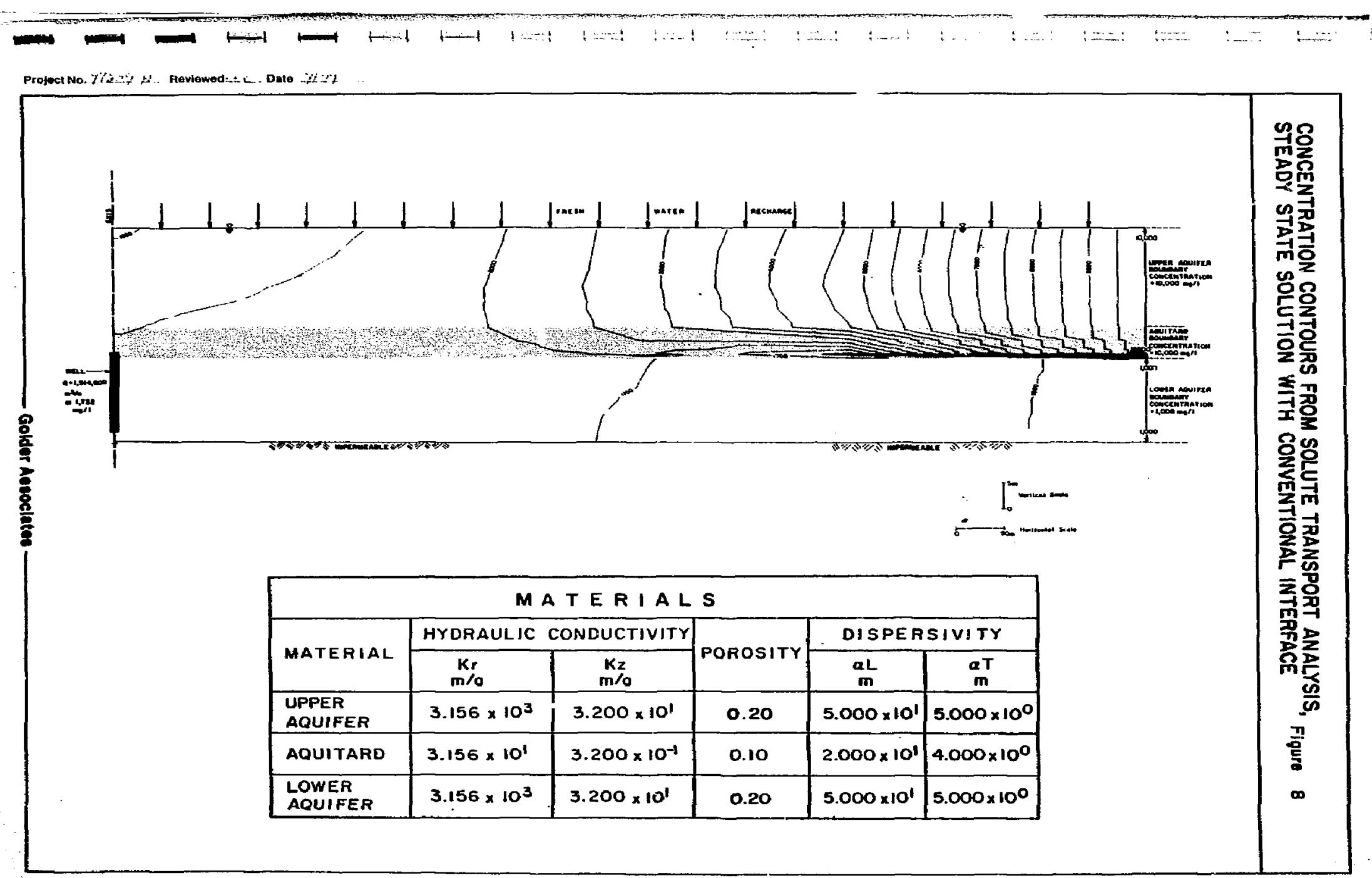


thin elements is very hard to predict. Third, it is convenient to use the same mesh for solute transport analyses which was used for the seepage analyses. The provision in advance of appropriate thin elements at troublesome interfaces would require an unusual degree of premonition or a lot of experimentation by the user.

One method of resolving the interface problem is to provide a spectal element, analagous to the interface elements used in structural mechanics problems (e.g., Ghaboussi et al, 1973). It would permit a discontinuity in the solute concentration at the interface while transmitting the correct quantity of solute across the interface. Interface elements yould be onedimensional, having zero thickness and two nodes at each end: one connected to the finite element on the "upstream" side and one to that on the "downstream" side.

It is apparent, based on the preceding discussion about outflow boundaries, that it pould be difficult for the interface elsments to identify correctly the quantity of solvte crossing the interface. Accordingly, a procedure was implenented in the SOLTR program which treated the upstream stde of the interface as an outflow koundary and the downstream side as an inflow boundary, using the boundary conditions presented in the previous section. The quantity of solute discharged from a node on the upstream side is simply adder to the node on the downstream side. Implementing this procedure involves the following steps.

1. "Split" the nodes on the interface 1nto two nodes, one attached to the "upstream" and the other to the "downstream" element.

2. Use the left-hand side of Equation [I] to compute the rate at which fiuid is discharged across the interface from the upstream to the downstream node. 
3. Add the fluid discharge rate to the diagonal term for the upstream node in the solute transport matrix.

4. Subtract the discharge rate from the off-diagonal term in the row of the downstream node and the column of the upstream node.

The abcve procedure was implemented in the SOLTR program and produced the results shown in Figure 9. These results appear to have completely overcon : the problems with discharging nodes and with internal interfaces. Based on the success of this approach, it ic intersating to speculai. isiuer some of the problems attributed by earlier researchers to "numerical Instability" or to discontinuities in the seepage velocity field might not in fact be caused by inadequate boundary cunditions or treatment of internal interfaces.

The new procedures were also effective in transient analyses. Figures 10, 11, and 12 show the development of the concentrations through time and Figure 13 shows the concentration of the pumped water as a function of time. ihe temporary bigh concentrations around 10 years' time are ameliorated by subsequent flushing through of fresh water drawn down from the depressed pater table. 


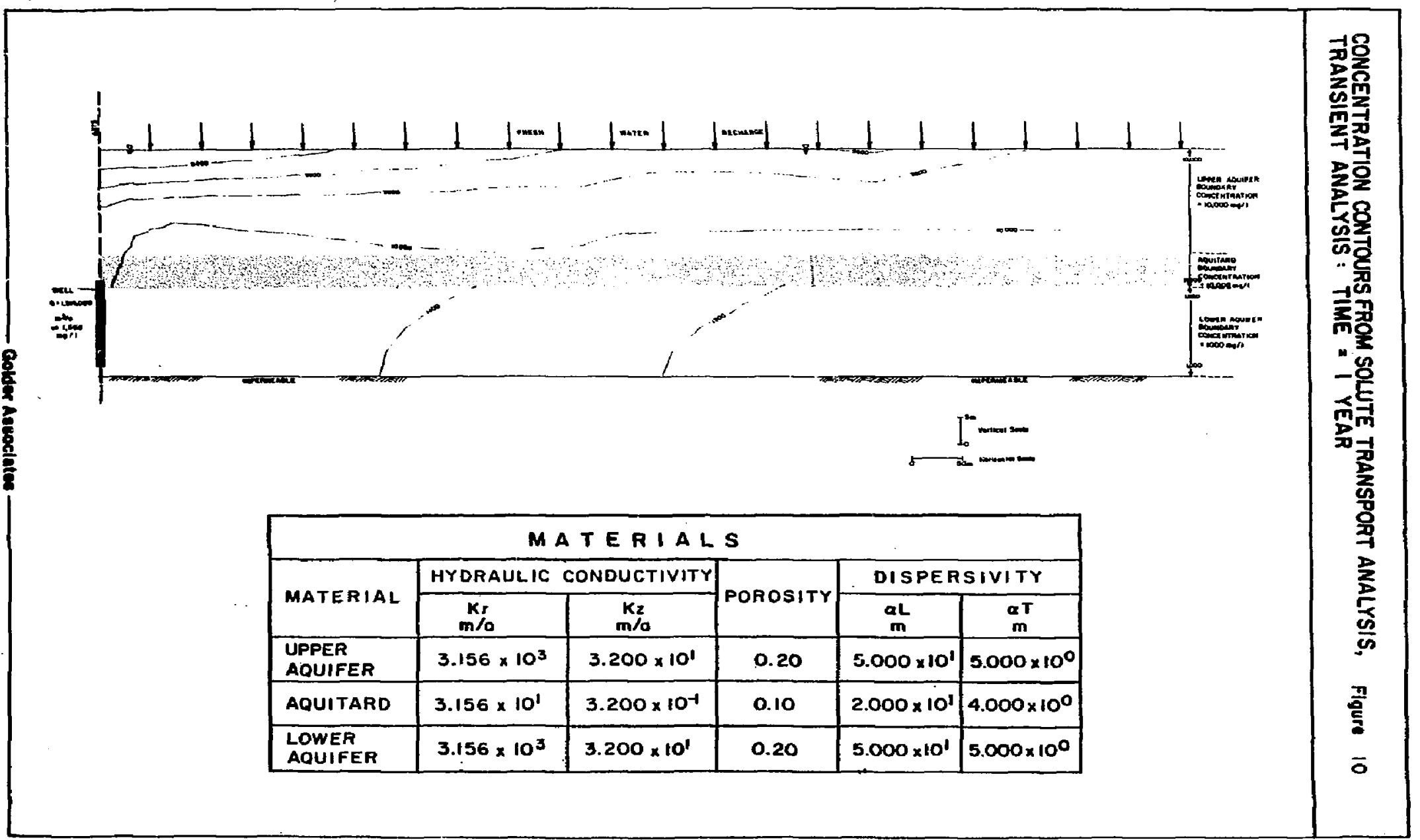




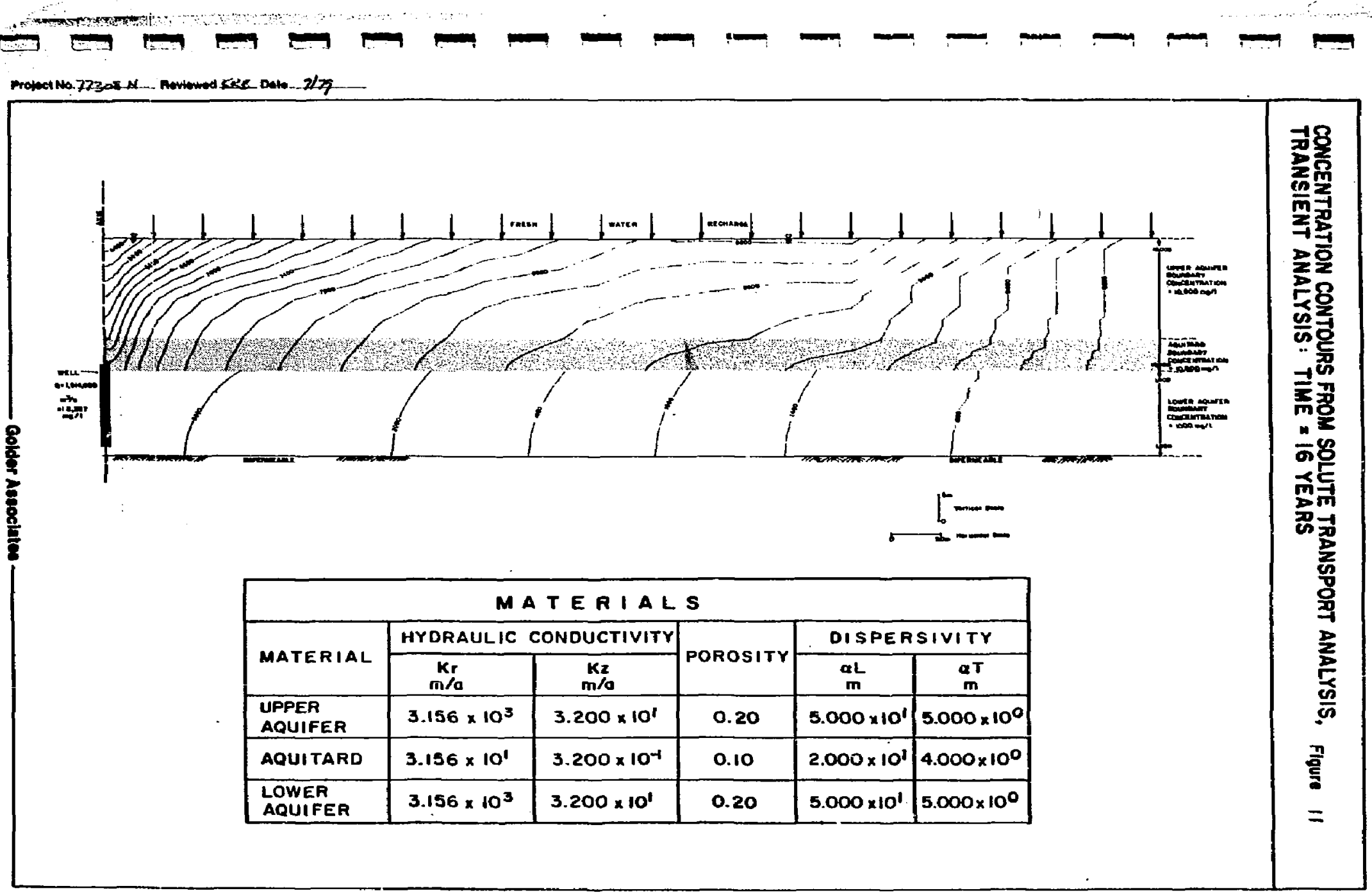


I

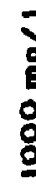

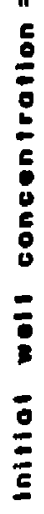

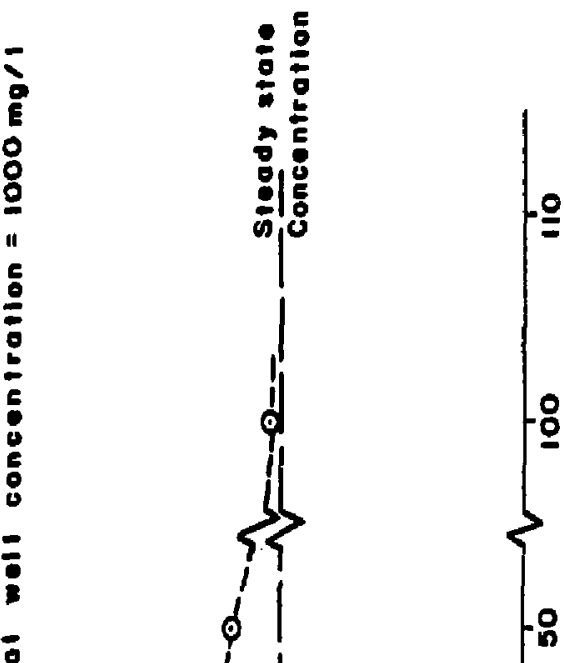

8

1

I

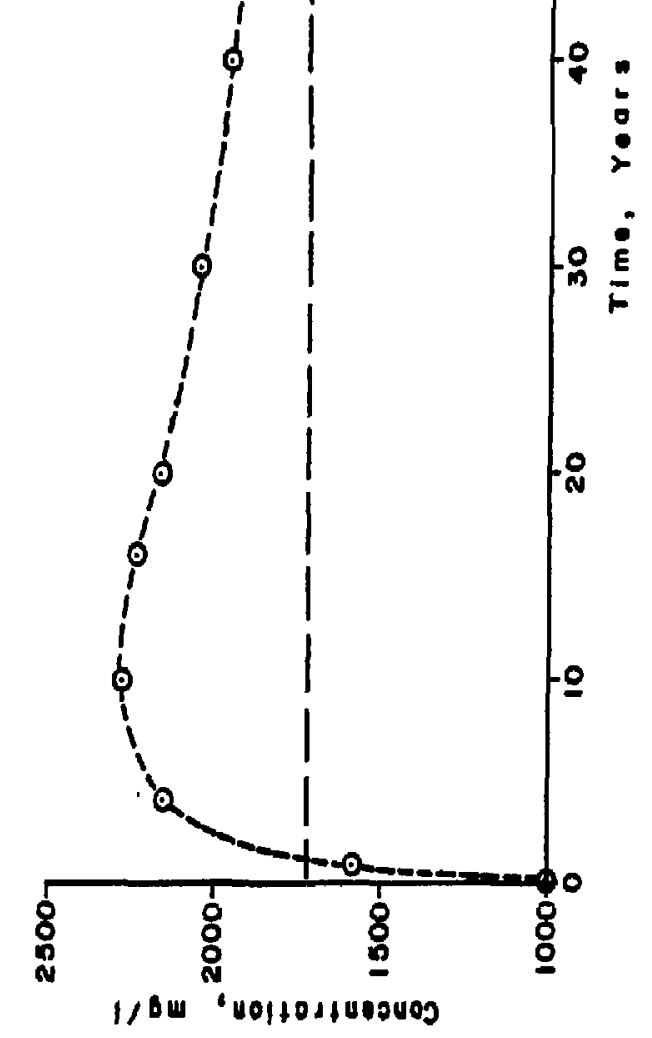


A widely reported phenowenon in numerical models of solute transport is the presence of numerical instability when dispersive effects are cutweighed by convective effects. In order to investigate the nature of this phonomenon in our model, we gradualig reduced the dispersivity in the test problem. As the dispersivity was decreased from the initial value (longitudibal dispersivity, $a_{L}=50 \mathrm{~m}$, lateral dispersivitg, $a_{T}=5 \mathrm{~m}$ ) the Interface between the fresh water recharging the water table and the $10,000 \mathrm{mg} / 1$ water coming from the right-hand boundary became more and more distinct. "Instability" did not occur until the dispersivity was reduced by a factor of $100\left(\alpha_{L}=0.5\right.$ $m, a_{T}=0.05 \mathrm{~m}$ ), at which time the computed steady-state concertrations vere as shown in Figure 14: The most striking result of instability shows up in the large elements near the outer radius and consists of a "bulge" of increased concentration $(12,000 \mathrm{mg} / 1)$ on the saline side of the $\mathrm{fresh} / \mathrm{salt}$ interface. The contours shown in Figure 14 are not smoothed (the plotting routine plots contours as straight lines between element sides).

A series of experiments was performed to see whether uprind weighting of the velghting functions in the finite elements would decrease the instability. The technique used was to augment the Galerkin weighting functions with 2 Dirac-delta collocation "spike" at the element centrold, yith the magnitude of the spike being positive when the node was downstream from the centrold and negative when it was upstream.

It was found important to maintain the sum of the spike amplitudes at each centroid equal to zero (more generally, it is necessary to have the sum of the relghting functions equal to unity at every point in a mesh in order to maintain a global 


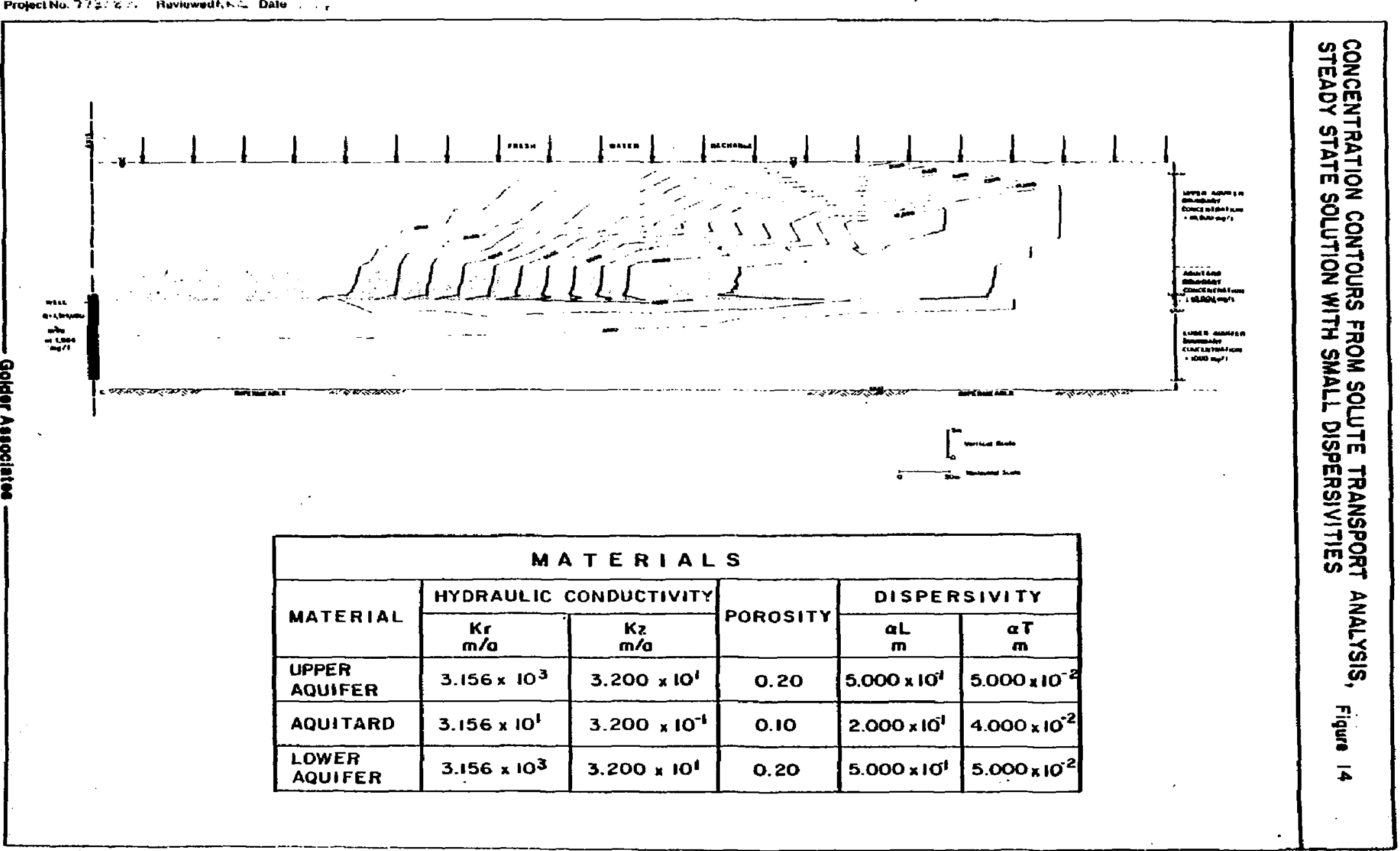


mass balance). The effectiveness of the procedure was limited, With moderate improvement in moderately unstable problems and little effect in badly unstable problems. It was concluded that upwind weighting could improve marginal solutions but was by no means a panacea for instability.

Analysis of the instability in this and other test problems seems to indlcate that it is caused by elements which are too large to conform to the solute plume. The instability tends to be local and to have little effect on results in regions where the mesh is of more suitable size. (Figure 24 shows the well produclag water at an average concentration of $1884 \mathrm{mg} / 1$--only 6 percent above the correct value of $1776 \mathrm{mg} / \mathrm{l}$.)

Due to the usually substantial dispersion in groundwater flow, problems with numerical instability are seldom encountered in practice. Based on the authors' experience, the tentative conclusion is advanced that, provided the finite elements are small enough for the solution to be able to conform to the solute plume, there $\$ 111$ be no difficulty with instability. In practice, it is usually practicable to predict the general nature of a solute plume (or an interface as in the sample problem) once the streamline directions and the dispersivities are known. For regional scale studies, preliminary analyses can be performed using coarse meshes and artiflclally high dispersivity, then repeated using true dispersivities and a refined mesh in the appropriate areas. 
7.0 CONCLUDING REMARKS

Although Galerkin fint te element analysis of solute transport has been in use for some time, there are st11l a number of problems which arise in 1ts everyday application. This report has discussed problems which arise at outflow boundaries, at internal interfaces between materials, and in convection dominated probiems. It is hoped that the discussion presented here w1ll be helpful to others, and will help stimulate discussion of other problems and solutions in solute transport analysis. 


\section{REPERENCES}

Christie, I., Griffiths, D. F., Mttchell, A. R., and Zienklewicz, 0 . C., 1976, Finite element methods for second order differential equations with significant first derivatives: Int. J. Num. Meth. Engng., v. 10, p. 1389-1396.

Duguid, J. O., and Reeves, M., 1976, Material transport through porous media: A flnite-element Galerkin model: Oak Ridge Nat. Laboratory, Environmental Sciences Division Publication 733.

Gartling, D. K., 1978, Some comments on the paper by Heinrlch et a1.: Int. J. Num. Meth. Engng, v. 12, p. 187-190.

Ghaboussi, J., E. L. M1lson, and Isenberg, J. 1973, Finite element for rock foints and interfaces: J. So11

Mech. Found. DIV., ASCE, SM10, p. 833-848.

Heinrich, J. C., Huyakorn, P. S., Zlenkiewicz, O. C., and Mitchell, A. R., 1977, An "Upwind" finite element scheme for two-dimensional convective-transpori equation:

Int. J. Num. Meth. Engng., v. 1l, p. 131-143.

Pinder, G. F., 1973, A Galerkin finite element simulation of groundwater contamination on Long Island, New York: Water Resources Res., จ. 9, no. 6, p. 1657-1669.

Segol, G., Pinder, G. F., and Gray, T. G., 1975, A Galerkin-finite element technique for calculating the transient position of the saltwater front: Mater Resour. Res., v. 11, no. 2, p. 343-347. 


\section{APPENDIX}

\section{DERIVATION OF GALERKIN FINITE ELEMENT EQUATIONS}


Derivations of Galerkin finlte element equations for solute transport can be found in various pacers (e.g., D1nder 1973 or, 10 more detall, Duguld and Reeves 1976). This Appendix presents a derivation which detalls how the equations are formed and how boundary conditions are incorporated.

The basic equation to be addressed is that of steady-state solute transport with external solute fluxes applied only at the boundaries. Additional terms for transient analysis, distributed Influx/outflux, retardation, decay, etc., are readily incorporated (see the above references) but are not presented here in order to simplify the equations. The basic equation for the mass rate of solute flux is:

$[A .1] \quad \underline{E}=(\underline{\underline{V}-E D V}) \mathrm{C}$

Where:

$\underline{F}$ is the solute flus velocity vector, $\left(M-2 \mathrm{~T}^{-1}\right)$

$\checkmark$ is the Darcy velocity, $\left(\mathrm{LT}^{-1}\right)$

$\varepsilon$ is the porosity

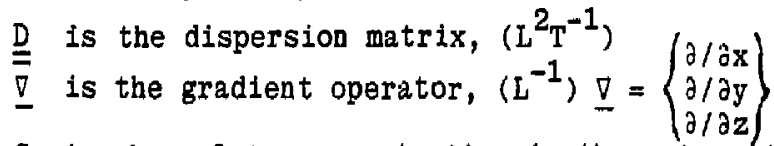

$C$ is the solute concentration in the witer, $\left(M L^{-3}\right)$

VC is the convective flux

EDVC Is the dispersive flux.

Note: A vector analysis notation is used in this section. Vector quantities have a single underscore, matrices a double underscore. 
Conservation of solute mass is ensured by setting the divergence of the flux to zero:

$$
\text { [A.2] } \underline{\nabla}^{T} \underline{F}=0
$$

where $\underline{\nabla}^{T}$ is the divergence operator $\left(L^{-1}\right) \cdot \underline{\nabla}^{T}=\langle\partial / \partial x, \partial / \partial y, \partial / \partial z\rangle$.

The finite element method approximates the solute concentration $\mathrm{C}$ within the elements by the product of the nodal concentrations with the nodal interpolation function:

$$
\text { [A.3] } \quad \mathrm{C}=\underline{\mathbb{N}}^{\mathrm{T}} \underline{\mathrm{C}}
$$

where:

N is a vector containing the values of the nodal interpolation functions at a point, one interpolation function per node;

$\underset{C}{C}$ is a vector containing the nodal concentrations $\left(M L^{-3}\right)$.

A finite element equation is then formed for each node by setting a weighted average of the governing equation (A.2) to zero. In the Galerkin method, the nodal weighting function ${ }_{1}$ is 1dentical to the node's interpolation function $N_{i}$ (when upwind weighting is used, $W_{I}$ is modified somewhat). Thus, the fintte element equation for node $i$ is:

$$
\text { [A.4] } \int \mathrm{W}_{1} \underline{\underline{\mathrm{T}}} \underline{\mathrm{F}} \mathrm{d} \Omega=0
$$

where $\Omega$ is the problem region.

It is necessary to consider the precise nature of the integration in Equation (A.4). First, in the finite element method the weighting function used is non-zero only within those elements which touch the node, thus limiting the necessary 
domain of integration when forming a node's equation. Second, it is possible for the integral to be singular at interelement or external boundaries. This difficulty is handled by integrating separately over the volumes of the elements and across their boundaries. Third, by assuming that the region extends to just outside the boundaries, it is possible to incorporate boundary conditions directly.

The integral across a boundary (either interelement or external) of the function $\underline{\nabla}^{T} \underline{\underline{F}}$ is simply the rate at which solute is "appearing" at the boundary:

$$
\int_{\substack{\text { across a } \\ \text { boundary }}}^{W^{T} \underline{F}=\nabla_{i} \Delta\left(\underline{n}^{T} \underline{F}\right)}
$$

where:

$\Delta$ is the difference between the two sides of the boundary;

$\mathrm{n}^{\mathrm{T}}$ is a unit outward normal vector;

$W_{i}$ is assumed to be continuous at the boundary (this can be important when defining upwind weighting functions).

Thus, Equation (A.4) is expanded as:

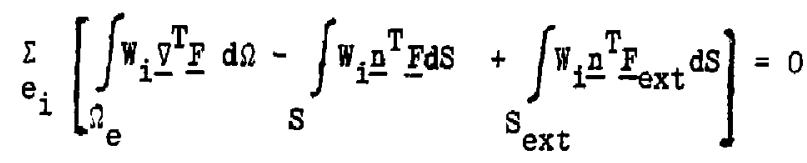

where:

$\sum_{i}$ is the sum over all elements which contain node $i$; $\Omega_{\mathrm{e}}$ is the region inside the element;

$S$ is the surface of the element;

$S_{\text {ext }}$ is that portion of the element surface thich is on the exterior boundary of the problem;

$F_{\text {ext }}$ is the specified solute flux rate just outside of the exterior boundary (often defined by $\underline{E}_{\text {ext }}=$ V $($ ext . 
The second and third integrals in (A.6) combine to make up the term $\mathbb{W}_{i} \Delta(\underline{\underline{T}} \underline{\underline{F}})$ defined in (A.5). Boundary conditions arise naturally from (A.6):

- At upstream boundaries where it is desired to fix the concentration no nodal equation is formed at all (or if formed, it is ignored in the matrix solution process).

- At boundaries where the flux across the boundary is known it is only necessary to specify $F_{\text {ext }}$. This is often the case at "upstream" boundaries.

- At discharging boundaries, it is reasonable to assume that the flux just outside the boundary is identical to that just inside it. This means that over the discharging boundary the last two integrals in (A.6) will cancel. Therefore, for discharging boundaries these integrals need not be computed.

As described in the text for non simple seepage velocity fields, it is more appropriate at discharge nodes to directly estimete the rate of fluid discharge contributed by node $i Q_{i}$. The removal of this quantity of fluid at node i's concentration substitutes for the last integral in (A.6), giving:

$$
\sum_{i}\left[\int_{\Omega_{e}} \pi_{i} \underline{\nabla}^{T} \underline{F} d \Omega-\int \pi_{i} \underline{n}^{T^{T}} \underline{T} d S\right]+Q_{i} C_{i}=0
$$

Equation (A.7) can be simplified by using the divergence theorem. First, note that the term $\mathbb{W}_{I} \underline{V}^{T_{F}}$ is equal to $\underline{\nabla}^{T}\left(W_{i} \underline{F}\right)-\left(\underline{\nabla}{ }_{i}\right)^{T} \underline{F}$. The divergence theorem states that:

$$
\int_{\Omega_{e}} \underline{\nabla}^{T}\left(W_{i} \underline{F}\right) d \Omega=\int_{S} \underline{n}^{T}\left(W_{i} \underline{F}\right) d S
$$


Substituting for $\%: \vec{F} \underline{F}$ in (A.7), and then applying (A.B), the surface integrals cancel, leaving:

$$
\text { [A.9] } \quad \sum_{i}\left[-\int_{\Omega_{e}}\left(\underline{\nabla W}_{i}\right)^{T_{\underline{F}} \mathrm{~d} \Omega}\right]+Q_{j} \mathrm{c}_{i}=0
$$

The upwind pelghting method used in the SOLTR program uses a collocation point at the element centroid, i.e.:

$$
\text { [A.10] } w_{i}=w_{i}+a_{i} \hat{i}\left(x-x_{i}, y-y_{i}, z-z_{i}\right)
$$

where:

$$
\begin{aligned}
& a_{i} \text { is the amplitude of the collocation yoint } \\
& \delta \text { is the Dirac delta. }
\end{aligned}
$$

When using upwind peighting as described in [A.10] the function $\mathbb{N}_{i} \mathbf{F}$ is not continuously differentiable and thus the divergence theorem cannot be directly applied. Equation [A.7] is thus the form used in SOLTR (though [A.9] could have been used by adding $a_{i} \nabla^{T_{F}}$ to [A.9], where $\underline{F}_{c}$ is the flux at the collocation point).

While the above derivation is undoubtediy more detailed than many readers pould like, it is hoped that it demonstrates that there can be mo:e to forming findte element equations than is immediately apparent. What has been presented is only a fragment of what is needed to build and solve finite element problems, but it represents a part not usually found in texts. 


\section{REPERENCES}

Christie, I., Griffiths, D. F., Mitchell, A. R., and Zienklerica, 0 . C., 1976, Finite element methods for second order differential equations with significant first derivatives: Int. J. Num. Keth. Engng., v. 10, p. 1389-1396.

Duguid, J. O., and Reeves, $\mathrm{H}_{*}, 1976$, Material transport through porous media: A flnite-element Galerkin model: Oak Ridge Nat. Laboratory, Environmental Sciences Division Publication 733 .

Gartilng, D. K., 1978, Some comments on the paper by Heinrich et al.: Int. J. Num. Meth. Engng, v. 12, p. 187-190.

Ghaboussi, J., E. L. T11son, and Isenberg, J. 1973, Finite element for rock foints and interfaces: J. Sofl

Mech. Found. Div., ASCE, SM10, p. 833-848.

Heinrıch, J. C., Huyakorn, P. S., Zienkiewicz, O. C., and Mitchel1, A. R., 1977, An "Upwind" finite element scheme for two-dimensional convective-transport equation: Int. J. Num. Meth. Engng., v. 11, p. 131-143.

Pinder, G. F., 1973, A Galerkin finite element simulation of groundwater contamination on Long Island, New York: Water Resources Res.; v, 9, no. 6; p. 1657-1669.

Segol, G., Pinder, G. F., and Gray, M. G., 1975, A Galerkin-finite element technique for calculating the transient position of the saltwater front: Fater Resour. Res., $\nabla .11$, no. 2, p. 343-347. 
APPENDIX

DERIVATION OF GALERKIN FINITE ELEMENT EQUATIONS

1

1

1

1

1

5

I

I

I

I

I 
Derivations of Galerkin finite element equations for solute transport can be found in varlous papers (e.g., P1nder 1973 or, in more deta11, Duguld and Reeves 1976). This Appendix presents a derivation which details how the equations are formed and how boundary conditions are incorporated.

The basic equation to be addressed is that of steady-state solute transport with external solute fluses applied only at the boundaries. Additional terms for transient analysis, distributed influx/outflux, retardation, decay, etc., are readily Incorporated (see the above references) but are not presented here in order to simplify the equations. The basic equation for the mass rate of solute flux is:

\section{[A.1] $\quad \underline{\underline{F}}=(\underline{\underline{V}-E D V}) \mathrm{C}$}

where:

$\underline{F}$ is the solute flux velocity rector, ( $\left.\mathbb{U}^{-2} \mathrm{~T}^{-1}\right)$

$\underline{\mathrm{V}}$ is the Darcy velocity, (LI-1)

$\varepsilon$ is the porosity

$\underline{D}$ is the dispersion matrix, $\left(\mathrm{L}^{2} \mathrm{~T}^{-1}\right)$

$\underline{\bar{\nabla}}$ is the gradient operator, $\left(L^{-1}\right) \underline{\nabla}=\left\{\begin{array}{l}\partial / \partial x \\ \partial / \partial y \\ \partial / \partial z\end{array}\right\}$

$C$ is the solute concentration in the mater, (ML-3)

VC is the convective flux

$E D V C$ is the dispersive flux.

Note: A vector analysis notation is used in this section. Vector quantities have a single underscore, matrices a double underscore. 
Conservation of solute mess is ensured by setting the divergence of the flux to zero:

[A.2] $\quad \underline{\underline{T}} \underline{\underline{F}}=0$

where $\underline{\nabla}^{T}$ is the divergence operator $(L-1), \underline{\nabla}^{T}=\langle\lambda / j \mathrm{x}, j / j \mathrm{y}, ; / j \mathrm{z}\rangle$

The finite element method approximates the solute concentration $C$ within the elements by the product of the nodal concentrations with the nodal interpolation functions:

$$
[A, 3] \quad C=\underline{N}^{T} \underline{C}
$$

where:

$N$ is a vector containing the values of the nodal interpolation functions at a point, one interpolation function per node;

$C$ is a vector contalning the nodal concentrations $\left(M L^{-3}\right)$.

A fintte element equation is then formed for each node by setting a weighted average of the governing equation (A.2) to zero. In the Galerkin method, the nodal welghting function $\pi_{i}$ is identical to the node's interpolation function $N_{i}$ (when upwind weighting is used, $\mathbb{W}_{i}$ is modified somewhat). Thus, the finite element equation for node $i$ is:

$$
\text { [A.4] } \int_{\Omega} \mathbb{P}_{i} \nabla{ }^{T} F d \Omega=0
$$

where $\Omega$ is the problem region.

It is necessary to consider the precise nature of the integration in Equation (A.4). First, in the finite element method the welghting function used is non-zero only within those elements which touch the node, thus limiting the necessary 
domain of integration when forming a node's equation. Second, it is possible for the integral to be singular at interelement or external boundaries. This difficulty is handled by Integrating separately over the volumes of the elements and across their boundaries. Third, by assuming that the region extends to just outside the boundaries, it is possible to incorporate boundary conditions directly.

The integral across a boundary (either interelement or external) of the function $\nabla^{T} \underline{\underline{F}}$ is simply the rate at wich solute is "appearing" at the boundary:

$$
\int_{i} \Psi_{i} \nabla^{T}=W_{i} \Delta\left(\underline{n^{T}} \underline{T}\right)
$$

where:

$\Delta$ is the difference between the two sides of the boundary;

$\underline{\mathrm{n}}^{\mathrm{T}}$ is a unit outward normal vector;

$W_{i}$ is assumed to be continuous at the boundary (this can be important when defining upwind weighting functions).

Thus, Equation $(A, 4)$ is expanded as:

(A.6) $\sum_{e_{i}}^{\sum}\left[\int_{l_{e}} W_{i} \nabla^{T} \underline{F} d \Omega-\int_{S} W_{i} \underline{n}^{T} \underline{F} d S+\int_{S_{e x t}} W_{i} \underline{n}^{T} \underline{F}_{e x t} d S\right]=0$

where:

$\sum$ is the sum over all elements which contain node $i$;

$\Omega_{j}$ is the reginn inside the element;

$S$ is the surface of the element;

$S_{\text {ext }}$ is that portion of the element surface which is on the exterior boundary of the problem;

Fext is the spectified solute flux rate just outside of the exterior boundary (often defined by $\underline{E}_{\text {ext }}=$ v(ext). 
The second and third integrals in $(A, 6)$ combine to make up the term $\mathbb{H}_{1} \Delta\left(\underline{n}^{\mathrm{T}} \mathrm{F}\right)$ defined in $(A .5)$. Boundary conditions arise naturally from $(A, 6)$ :

- At upstream boundarles where it is desired to $11 x$ the concentration no nodal equation is formed at all (or if formed, it is ignored in the matrix solution process).

- At boundaries where the flux across the boundary is known it is only necessary to specify $\underline{F}_{\text {ext. }}$. This is often the case at "upstream" boundarles.

- At discharging boundaries, it is reasonable to assume that the flux just outside the boundary is identical to that just inside it. This means that over the dscharging boundary the last two integrals in (A.6) will cancel. Therefore, for discharging boundaries these integrals need not be computed.

As described in the text for non simple seepage velocity fields, it is more appropriate at discharge nodes to directly estimate the rate of eluid discharge contributed by node $i Q_{i}$. The removal of this quantity of fluid at node $i$ 's concentration substitutes for the last integral in (A.6), giving:

$[A, 7] \quad \sum_{i}\left[\int_{\Omega_{e}} W_{i} \underline{\nabla}^{T} \underline{F} d \Omega-\int_{S} W_{i} \underline{n}^{T} \underline{F} d S\right]+Q_{i} C_{i}=0$

Equation (A.7) can be simplified by using the divergence theorem. First, note that the term $\mathbb{N}_{i} \underline{\underline{\underline{T}}} \underline{\underline{F}}$ is equal to $\underline{\nabla}^{T}\left(\mathbb{W}_{i} \underline{F}\right)-\left(\underline{\nabla}_{i}\right)^{T} \underline{F}$. The divergence theorem states that:

$$
\int_{\Omega^{2}} \underline{\nabla}^{\mathrm{T}}\left(W_{i} \underline{F}\right) d \Omega=\int_{S} \underline{\mathrm{n}}^{\mathrm{T}}\left(W_{i} \underline{F}\right) \mathrm{dS}
$$


Substituting for $4: \nabla^{-1} \underline{E}$ in $(A .7)$, and then applying $(A, 8)$, the surface integrals cancel, leaving:

[A.9] $\xi_{i}\left[-\int_{\Omega_{e}}\left(\underline{\nabla}_{i}\right)^{T} \underline{\underline{F}} d \Omega\right]+Q_{i} c_{i}=0$

The upwind weighting method used in the SOLTR program uses a collocation point at the element centroid, i.e.:

$[A .10] \quad W_{1}=N_{1}+a_{i} j\left(x-x_{1}, y-y_{i}, z-z_{i}\right)$

Where:

$a_{i}$ is the amplitude of the collocation point

$\delta$ is the Dirac delta.

Then using upwind weighting as described in [A.10] the function $\mathbb{N}_{1}$ is not continuousiy differentiable and thus the divergence theoren cannot be directly applied. Equation [A.7] is thus the form used in SOLTR (though [A.9] could have been used by adding $a_{1} \nabla \underline{F}_{C}$ to $[A .9]$, where $\underline{F}_{C}$ is the flux at the collocation point).

While the above derivation is undoubtedly more detalled than many readers would like, it is hoped that it demonstrates that there can be more to forming finite element equations than is immediately apparent. What has been presented is only a fragment of what is needed to build and solve finite element problems, but it represents a part not usually found in texts. 